\title{
Measuring the Effect of Confirmatory Bias on the Level of Investment at the Rwandan Stock Market
}

\author{
Jacob Niyoyita Mahina ${ }^{1}$, Wilson Bashaija ${ }^{2}$ \\ ${ }^{1}$ Department of Business Studies, University of Tourism, Technology and Tourism, Kigali, Rwanda \\ ${ }^{2}$ School of Entrepreneurship, Jomo Kenyatta University of Agriculture Technology, Nairobi, Kenya
}

Email address:

niyomhj1@gmail.com (J. N. Mahina), wilsonbashaija17@gmail.com (W. Bashaija)

\section{To cite this article:}

Jacob Niyoyita Mahina, Wilson Bashaija. Measuring the Effect of Confirmatory Bias on the Level of Investment at the Rwandan Stock Market. European Business \& Management. Vol. 4, No. 3, 2018, pp. 67-74. doi: 10.11648/j.ebm.20180403.11

Received: April 1, 2018; Accepted: April 26, 2018; Published: July 12, 2018

\begin{abstract}
Behavioural finance is still a new arear which attempt to better understand and explain how emotional and cognitive errors influence investment on the stock markets. The main objective of this study was to establish the effect of confirmatory bias on investment in the Rwanda Stock Exchange. The study used cross-sectional descriptive survey research design to ascertain and establish the effect of behavioural biases on investment in the Rwanda stock exchange. The target population comprised of 13,543 individual, group investors at the Rwanda Stock Exchange. Random sampling was used where the targeted population was individual investors to finally yield a sample size of 374 respondents. A questionnaire was used to collect the primary data. A pilot test was undertaken by carrying out a small scale trial run of the research instrument. Data analysis involved the use of descriptive and inferential statistics. A Linear regression model was used to predict the probability of different possibility outcomes of dependent variables, helping to predict the probability of an investor to invest in RSE. The results confirmed that there was a significant positive linear relationship between confirmatory bias and Investment in Rwanda stock market. The study also concluded that most investors suffered from confirmatory bias in investment in stock markets. The study recommends that investors should be keen to identify such bias to increase their rationality in stock trading.
\end{abstract}

Keywords: Confirmatory Bias, Investment, Rwanda, Stock Exchange

\section{Introduction}

\section{Background of the Study}

Behavioural finance is the new field that seeks to combine behavioural (aspirations, cognition, emotions) and cognitive psychological theory. It explains why investors makes a rational financial decisions on the stock market It describes the outcomes of interactions between investors and managers in financial and capital markets; and it prescribes more effective behaviour for investors and managers. The investment is mostly influenced in a large proportion by psychological and emotional factors [39].

Behavioural finance attempt to better understand and explain how emotional and cognitive errors influence investment on the stock markets The stock markets are able to positively influence the economic growth through encouraging savings amongst individuals and providing avenues for firm financing. Liquid stock markets may improve the allocation of capital and enhance prospects for long-term growth [41].

Investment is not an easy process, since the assumption is that investors always expect to maximize the returns although not all investors are so rational Traditional financial theories assume that investors are rational and risk averse, and hold diversified, optimal portfolios However, this doesn't work in reality since investors must consider the behavioural biases in investing as this can help the investors to avoid some unnecessary mistake made in investment in order to maximize the return and minimize the risk [39]; [3].

According to Shefrin bias is nothing else yet the inclination towards failure [35]. Bias is tendency to make decisions while the decision maker is already being subjected to an underlying credence or belief. There are so many biases in human psychology [36] These biases lay impact on individuals in such a way that they frequently deed on an obviously silly way, routinely disregard conventional ideas of risk aversion, and make foreseeable lapses in their conjectures and judgments [39]. 
These biases play their part in shaping individual's choices, financial decisions in corporations and financial markets. Unreasonable choices hamper the investor's wealth and the execution of companies and additionally the productivity of business sector. Scholars have identified so many biases [14] wrote a paper in which they stated different states of mental biases that may impact the investment process; they are risk aversion, regret aversion and selfattribution and the locus of control [1].

According to Lam, the investors' predictions of the market fluctuations with certain methods may be technical or fundamental analysis used to predict money market [18]. Technical analysis is used in forecasting stock price fluctuations while fundamental analysis attempts at differentiating the investment approach [11].

African stock markets have historically offered a limited, narrow range of products with the principle role of financial sector being the provision of the source of domestic funding to offset government budgetary deficits. Common factors still inhibiting stock market development include the lack of legal protection for investors and creditors Other constraints are that most African Stock Exchanges have limited trading hours and are closely synchronized with other regional markets Trading in the majority of markets is overwhelmingly dominated by a handful of stocks, even if more securities are actually listed and bulk trading of a limited number of stocks in the smaller exchanges hinders activity on the domestic markets The first stock exchange in sub Saharan Africa was Zimbabwe Stock Exchange (ZSE), the official stock exchange of Zimbabwe which started in 1948. It has 64 listed companies and opened to foreign investment since 1993 Zimbabwe Stock Exchange was established after Egyptian Exchange stock (EGX) which started in 1883. The EGX is the largest in Africa with 833 listed companies followed by Johannesburg Security Exchange or JSE that started in 1887 and in 2003 had an estimate of 472 listed companies. The Nigeria Stock Exchange (NSE) stated in 1960 and it has a population of 223 listed companies [23].

Prices in the African stock markets tend to be highly volatile and enable profits within short periods. Critics point out that the actual operation of the pricing and takeover mechanism in well-functioning stock markets lead to short term and lower rates of long term investment. This is because prices react very quickly to a variety of information influencing expectations on financial markets [20].

These problems are further magnified in developing countries especially sub-Saharan African economies like Rwanda, with their weaker regulatory institutions and greater macroeconomic volatility The higher degree of price volatility on stock markets in developing countries reduces the efficiency of the price signals in allocating investment resources. These serious limitations of the stock market have led many analysts to question the importance of the system in promoting economic growth in African countries [6].

Some of the common mistakes made by investors in designing their investment are identified as follows: investors fail to design their investment avenues systematically; investors fail to diversify their investment choice [39]; investors generally overestimate their skills, attributing success to ability they don't possess and seeing order in information or data where it doesn't exist i.e., investors are overconfident while making investment; investors blindly follow the crowd (herd mentality) while making investment which leads to wrong investment; investors anchor on historical information; investors think that good times are permanent They feel that ones they earn a good profit from their investment avenue, the investment would give them good returns permanently; investors are greed and they want to earn money quickly (instant gratification) which also leads to wrong investment. Finally, investor's generally make short term investments rather than long term investments [34].

Rwanda is one of the youngest stock market in East Africa with a small number of listed companies and low market capitalization, an indicator of low Stock Market development The Rwanda Stock Exchange Limited (RSE) was incorporated in 2005 and launched officially in 2008. It is the principal stock exchange operating under the jurisdiction of Rwanda's Capital Market Authority (CMA), previously known as Capital Markets Advisory Council (CMAC), which in turn reports to the (MINECOFIN) Ministry of Finance and Economic Planning Rwanda's Stocks Exchange is young compared to the other markets in EAC, like Nairobi Security Exchange (NSE) which was established in 1954, Dares Salaam Security Exchange in 1996 and Uganda Stock Exchange in 1997. Currently RSE has only three Initial Public Offering (IPO), Bralirwa, Bank of Kigali and Crystal Ventures as primarily listed in Rwanda and four IPO as secondarily listed in Rwanda includes: Kenya Commercial Bank Group and Nation Media Group, which are primarily listed in Nairobi Stock Exchange and cross listed on the Rwanda Stock Exchange [15].

The government has ensured that investors in the Rwanda Stocks Exchange are protected, by advising and guiding companies seeking investment through provision of important infrastructures and conducive environment for business development [22].

Despite these efforts, investment in the Rwanda stock exchange is low and the Rwanda Stocks Exchange is not growing at the pace expected. Currently there are approximately 13,543 registered investors, all these investors are composed by the individual investors, group investors and institutional investors. The market capitalization of Rwanda Stocks Exchange is USD 3.7 billon with 7 listed companies In comparison with Nairobi Securities Exchange, there are approximately 66 listed companies with a total market capitalization of approximately USD 23 billion [26].

\section{Literature Review}

\section{Theoretical Background}

There are a number of theories that explain the relationship between behavioral biases and investment decision. These 
include herding behaviour theory, prospect theory and heuristics theory. In addition, Marchand states that heuristics stands for the tendency those individuals make judgments quickly [21]. Heuristics are strategies used to access complex problems and limit the explaining information. Investors tend to make rules of thumb in order to process the information so that they can make investment. Waweru, Mwangi, \& Parkinson proposed that herding can drive property trading and create the momentum for trading [42]. In the case of Rwanda Stock Exchange, the impact of herding behaviour may break down when it reaches a certain level because the cost to follow the herd may increase to get the increasing abnormal returns.

Choices are made when people tend to give losses more weight than gain, where they focus on how much they gained or lost instead of how much they gained. Choices are also made where people are interested in their gains and losses as opposed to their final income and wealth. In the case of investment choice in the Rwandese Stock Exchange, investors may attribute choice of investments to own initiatives leading to self-attribution bias [13].

In general, heuristics are quite useful, particularly when time is limited [43], but sometimes they lead to biases In addition, March and states that heuristics stands for the tendency that individuals make judgments quickly [21]. Heuristics are strategies used to access complex problems and limit the explaining information. Investors tend to make rules of thumb in order to process the information so that they can make investment.

\section{Empirical Literature Review}

Though the literatures of behavioural finance are very large, some of the empirical cases of behavioural finance, which are based on the psychology, attempt to understand how behavioural biases and cognitive errors influence individual investors' behaviours [5].

Parmley conducted a study on the effects of the confirmation bias on diagnostic decision making. The purpose of this study was to examine the possible effects of the confirmation bias in psych diagnostic assessment, and to examine the effectiveness of educating clinicians specifically about the confirmation bias. There was also some evidence to suggest that those participants who identified their orientation as cognitive behavioural performed more accurately. The results hold important implications about commonly occurring biases in the psycho diagnostic assessment process [30].

Sadi, Asl, Rostami, Gholipour, \& Gholipour tried to recognize the popular perceptual errors among investors and its connection with their personality. 200 of the investors in Tehran's stock market were taken randomly as samples and the needed data was gathered through questionnaire. By using the parametric analysis and correlation they have tried to check the accuracy of the hypotheses. The finding demonstrated that the offered perceptual errors have got a significant correlation with the investors' personality. The conclusions exhibited that there is direct correlation between extroversion and openness with hindsight bias and over confidence bias, between neuroticism and randomness bias, between escalation of commitment and availability biases [33].

Veeraraghavan \& Anbalagan tried to establish the relationship between the heuristic behavioural factors and the investment decisions of the investor [40]. The study categorized the Investors into three categories, i.e., Risk Avoiders, Risk Takers and Risk Neutralists and also identified eight dominant heuristic behavioural factors. These decision biases in each of the heuristic factor varied from investor to investor depending on what category the investor fall i.e., Risk Avoiders, Risk Takers and Risk Neutralists. The study concluded the economic decisions of a human being are more emotionally based than rationally based.

Gholizadeh, Shakerinia, \& Sabet studied the effect of behavioural financial knowledge on the behaviours of the investors in Tehran Stock. The research studied six behavioural biases, viz., compatibility, familiar concept, idealistic belief, event oriented, fresh pot, irreversibility. Data was collected through a questionnaire. Investors of Tehran stock were interviewed for filling up the questionnaire. Structural equation method was used for analysis of the data. The results showed that only event-oriented bias doesn't have meaningful relationship with investor's decisions [8].

Bashir, Rasheed, Raftar, Fatima, \& Maqsood investigated the impact of behavioural biases on investor's financial decision making. Behavioural biases including overconfidence, confirmation, and illusion of control, loss aversion, mental accounting, status quo and excessive optimism were studied in the research. Questionnaire was used for data collection. Correlation and Linear regression model techniques were used to investigate whether investor decision making is affected by these biases. The study concluded that the Confirmation, Illusion of control, Excessive optimism, Overconfidence biases have direct impact on the investor's decision making while status quo, Loss aversion and Mantel accounting biases have no impact according to data collected from financial institutions [2].

Onsomu tried to identify behavioural biases which affect individual investors at the Nairobi Securities Exchange. The relationship between gender and the behavioural biases was also investigated in the study. The study was conducted by issuing questionnaires to investors of Nairobi Securities Exchange, Kenya. A total of 58 investors responded of which $69 \%$ were men and $31 \%$ were women. Collected data was analysed using descriptive statistics and Pearson Chi-square test [29]. Pearson Chi-square technique was used to analyse the relationship between gender and the behavioural biases. The results indicated that investors are affected by Availability bias, Representativeness bias, Confirmation bias and Disposition effect. Overconfidence bias has no significant effect because less than $50 \%$ of the investors were affected. There was no significant correlation between Availability bias, Representativeness bias, Confirmation bias, Disposition effect and Overconfidence bias and gender. 


\section{Research Methodology}

The underlying epistemology of this research was positivist; focusing on examining earlier established theories under the assumption that reality is objectively given and can be described by measurable properties independent of the observer and the instruments.

The study used cross-sectional descriptive survey research design to assess and establish the effect of behavioural biases on investment at the Rwanda stock exchange. The design was suitable for the proposed study because it attempted to determine current status of the phenomenon. The crosssectional descriptive survey method was suitable for this study since data was collected at one particular time [37] across the respondents in the Rwanda Stock Exchange. The target population of this study comprised of individual, group and institutional investors at the Rwanda Stock Exchange which are approximately 13,543 RSE, 2015. There are approximately 10,662 local investors, 2,474 from EAC and 407 registered as foreigner investors, all these investors are composed by the individual investors, group investors and institutional investors [32].

Stratified random sampling was used and it involved dividing the population into homogeneous subgroups followed by a simple random sample [16].

To determine the sample size for small populations, we use the normal approximation to the hyper-geometric distribution, similar studies [25] have adopted the hypergeometric distribution due to its ability to estimate sample sizes from small populations accurately. The sample size formula for small (hyper-geometric) populations is shown as follows:

$$
n=\frac{N Z^{2} p q}{\left(E^{2}(N-1)+Z^{2} p q\right.}
$$

Where; $n=$ is the required sample size

$\mathrm{N}=$ is the population size $(13,543)$

$\mathrm{Z}=$ is the level of confidence of the sample size (set at $95 \%$ ) thus $Z=1.96$

$\mathrm{P}$ and $\mathrm{q}$ are the population proportions (Each set to 0.5 ).

$E$ sets the accuracy of the sample proportions (set to 0.05 ).

Therefore;

$$
\frac{13543 \times 1.96^{2} \times 0.5 \times 0.5}{0.05^{2}(13543-1)+1.96^{2} \times 0.5 \times 0.5}
$$

\section{$\mathrm{n}=13006.6972 \div 34.8154$}

Hence, 374 was the suitable sample size for the population of 13543 investors from Rwanda Stock Exchange. The sample size is 374 , were selected using the simple random sampling. A semi-structured questionnaire was used to collect the primary data. The semi-structured questionnaire was designed to contain both closed and open-ended questions and a five-point Likert scale. The questionnaire was divided into three parts: (a) demographic information (b) investment (c-g) information on biases. Data analysis involved the use of descriptive and inferential statistics in order to help the researcher to establish the relationship between emotional bias and investment. Descriptive statistics such as mean, standard deviation and the inferential techniques such as regression and correlation will be used as well. Data was also analyzed and expressed in terms of charts and tables for quick references. In relation to inferential statistics, the linear and multi linear regression models were utilized to further give inferences to the data obtained using the Statistical Package for Social Sciences (SPSS). The study used the model below to test the hypothesis.

$\mathrm{Y}=\beta_{0}+\beta_{1} \mathrm{X}_{1}+\varepsilon$

Where:

$\mathrm{Y}=$ Investment in Rwanda stock Exchange

$\beta_{0}=$ Constant

$\beta_{1} \cdot \beta_{4}=$ Represents the regression coefficients

$\mathrm{X}_{1}=$ Confirmatory bias

$\varepsilon=$ Represents the error term

HO: Confirmatory bias has no significant effect on the level of investment at the Rwandan Stock Exchange.

\section{Results and Discussions}

The study administered a total of 374 to selected individual investors in Rwanda stock market. A total of 350 questionnaires were dully filled and returned. This represented a response rate of $93.6 \%$.

\subsection{Respondents Background Information}

Table 1 presents the demographic characteristics of the respondents. This was aimed at describing the sample that was used in this study. The study sought to establish the age bracket of the respondents, genders of the respondents and there highest education qualifications.

Table 1. Respondents background information.

\begin{tabular}{lll}
\hline Bio Data & Response & Percent \\
\hline Age & $21-30$ years & 48.3 \\
& 31-40years & 41.4 \\
& $41-50$ years & 3.4 \\
& $51-60$ years & 6.9 \\
& & \\
Gender & Male & 68.9 \\
& Female & 31.1 \\
& & \\
highest level of education attained & Undergraduate & 20.9 \\
& Graduate & 65.1 \\
& Post Graduate & 14 \\
Total & & 100 \\
\hline
\end{tabular}

\subsection{Descriptive Results}

Table 2 contains the descriptive findings on the effects of confirmatory biases on investment in the Rwandan stock market. 
Table 2. Descriptive results on confirmatory bias.

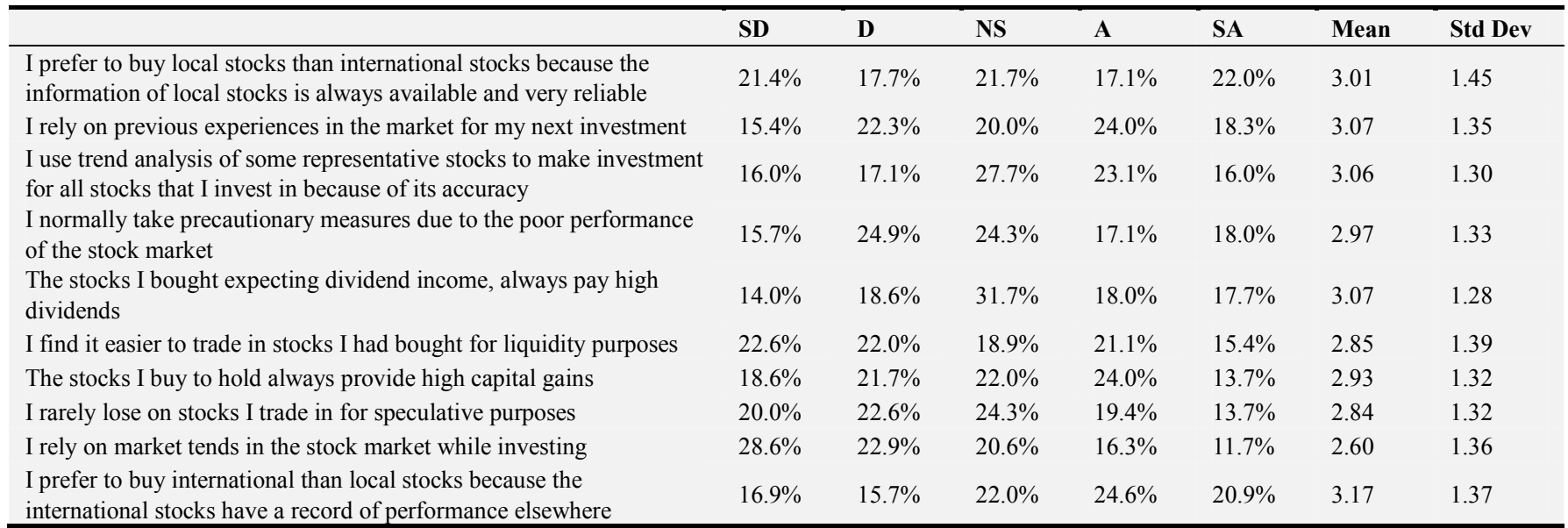

The study sought to find out whether investors at Rwanda stock markets preferred to buy local stocks than international stocks because the information of local stocks was always available and very reliable, the result showed that $21.4 \%$ strongly disagreed, $17.7 \%$ disagreed, $22.0 \%$ strongly agreed while $17.1 \%$ agreed. Those who were not sure were $21.7 \%$. These finding implied that investors at Rwanda stock market did not have priorities in terms of local and international companies.

The results also showed that $24.0 \%$ and $18.3 \%$ of the respondents agreed and strongly agreed that they relied on previous experiences in the market for my next investment. Those who disagreed were $37.7 \%$. These findings implied that some of the investors relied on previous experience while other did not rely on previous experience which was confirmed by the mean of 3.07 meaning respondents had almost contradicting responses. On whether respondents used trend analysis of some representative stocks to make investment for all stocks that they invest in because of its accuracy, the results revealed that majority of the respondents agreed.

The study further sought to find out whether the investors normally took precautionary measures due to the poor performance of the stock market, the results revealed that $24.9 \%$ disagreed, $24.3 \%$ were not sure, $18.0 \%$ strongly agreed and $17.1 \%$ agreed. The statement had a mean of 2.97 which indicated that those who agreed and those who disagreed were almost equal. These fining implied that some of the respondents took precautionary measures due to the poor performance of the stock market while other did not.

The study also intended to establish whether the stocks investors bought expecting dividend income, always paid high dividends. The findings showed that $18.0 \%$ agreed, $17.7 \%$ strongly agreed, $31.7 \%$ were not sure. On the other hand, $18.6 \%$ and $14.0 \%$ disagreed and strongly disagreed respectively. The findings implied that for some investors stocks bought expecting dividend income, always paid high dividends while for other it did not.

On whether investors at Rwanda stock exchange found it easier to trade in stocks they had bought for liquidity purposes, almost half of the respondents (44.6\%) disagreed, those who agreed were $36.5 \%$. the findings implied that the respondents still found it not easier to trade in stock they had bought for liquidity purposes. The findings also showed that $24.0 \%$ and $13.7 \%$ of the respondents agreed and strongly agreed that stocks they bought to hold always provided high capital gains. Those who disagreed with the statement were $40.3 \%$ while remaining were not sure.

The study sought to establish whether investors at Rwanda stock market rarely lost on stocks they trade in for speculative purposes. The findings showed that $20.0 \%$ and $22.6 \%$ strongly disagreed and disagreed respectively. On the other hand, those who agreed were $33.1 \%$. These findings was an indication that some investors at Rwanda stock market lost on stocks they trade in for speculative purposes while others did not. The finding implied that whether stock is traded in for speculative purposes or not, there was still a probability of losing.

The study further sought to establish whether the respondents relied on market tends in the stock market while investing, the results for this study showed that $51.5 \%$ of the respondents disagreed while $28.0 \%$ agreed. The finding implied that most of the investors did not rely on the trend in the market when investing. The study finally, sought to find out whether, investors at Rwanda stock market preferred to buy international than local stocks because the international stocks have a record of performance elsewhere, the finding showed that slightly below half $(45.5 \%)$ of the respondents agreed with the statement while $31.6 \%$ of the respondents disagreed. The findings implied that some of the investors preferred investing in international stocks while others preferred local stock.

These findings implied that investors at Rwanda stock market suffered from confirmatory bias. This is because when investors have already made their choices only search for information to confirm their preconceptions A study by [10] also showed that an investor may suffer not merely from overconfidence, but also from wrongness when the investor's confirmatory bias is severe enough. [17] study on the other hand found that show that an investor exhibiting confirmatory bias may come to believe with near certainty in a false hypothesis despite receiving an infinite amount of information. 


\subsection{Correlation Tests}

The researcher investigated the association between the dependent variable and the independent variables as well as between the independent variables themselves using the correlation coefficient matrix as recommended by [7] as shown in table 3 .

Table 3. Correlation results.

\begin{tabular}{lll}
\hline & & Confirmatory Bias \\
\hline Confirmatory Bias & Pearson Correlation & 1 \\
& Sig. (2-tailed) & \\
Investment In RSE & Pearson Correlation & 0.487 \\
& Sig. (2-tailed) & 0.000 \\
& $\mathrm{~N}$ & 350 \\
\hline
\end{tabular}

The findings also established that the correlation between Investment in Rwanda Stock Market by individual investors at the Rwanda stock market and Confirmatory Bias was
0.487 with a corresponding $\mathrm{p}$ value of 0.000 . These findings implied that there existed a positive and significant association between Confirmatory Bias and Investment in Rwanda Stock Market by individual investors at the Rwanda stock market. Similarly, [17] study showed that an investor exhibiting confirmatory bias may come to believe with near certainty in a false hypothesis despite receiving an infinite amount of information which may lead them to over invest.

\subsection{Regression Results for Confirmatory Bias and Investment in RSE}

The study employed a linear regression analysis to test the relationship between independent variables and the dependent variable. According to [9], regression is the determination of a statistical relationship between two or more variables. In simple regression, there are two variables, one variable (defined as independent) is the cause of the behavior of another one (defined as dependent variable).

Table 4. Model results for confirmatory bias.

\begin{tabular}{lllll}
\hline Model & R & R Square & Adjusted R Square & Std. Error of the Estimate \\
\hline 1 & .487 & .237 & .235 & .42995 \\
\hline
\end{tabular}

Similarly, findings revealed a relationship $\mathrm{R}=0.487$, indicating a strong positive association between confirmatory bias and investment in Rwanda stock market. R-squared $=0.237$ indicated that $23.7 \%$ of variation in the investment in Rwanda stock market can be explained by confirmatory bias.

Table 5. Anova results for confirmatory bias.

\begin{tabular}{lllllll}
\hline Model & & Sum of Squares & df & Mean Square & F & Sig. \\
\hline \multirow{3}{*}{1} & Regression & 19.950 & 1 & 19.950 & 107.923 & .000 \\
& Residual & 64.330 & 348 & .185 & & \\
& Total & 84.280 & 349 & & & \\
\hline
\end{tabular}

The results of ANOVA test show that the F value is 107.923 with a significance of $p$ value $=0.000$ which was less than 0.05 , meaning that there is a relationship between confirmatory bias and investment in Rwanda stock market.

Table 6. Regression results for confirmatory bias and investment in RSE.

\begin{tabular}{lllll}
\hline & B & Std. Error & Beta & t \\
\hline (Constant) & 3.031 & 0.07 & & 43.205 \\
Confirmatory Bias & 0.224 & 0.022 & 0.487 & 0.000 \\
\hline
\end{tabular}

The model $Y=\beta_{0}+\beta_{1} X_{1}+\varepsilon$ therefore became Investment in Rwanda stock market $=3.031+0.249$ (Confirmatory Bias) $+\varepsilon$.

The results on the beta coefficient of the resulting model showed that the constant $\alpha=3.031$ is significantly different from 0 , since the $\mathrm{p}$ - value $=0.000$ is less than 0.05 . The coefficient $\beta=0.224$ is also significantly different from 0 with a $\mathrm{p}$-value $=0.000$ which is less than 0.05 . The results imply that change in confirmatory bias will result in 0.224 units change in Investment in Rwanda stock market. This confirmed that there was a significant positive linear relationship between confirmatory bias and Investment in Rwanda stock market. Similarly, [17] study showed that an investor exhibiting confirmatory bias may come to believe with near certainty in a false hypothesis despite receiving an infinite amount of information which may lead them to over invest.

\section{Conclusions}

The study finally concluded that confirmatory bias play a positive and significant role in frequency of trading in stock market. Confirmatory bias limits investors from making sound decisions based on the reality which may sometimes results to over trading or reduced trading. Investors therefore should take note of these biases and consult widely before making investment decisions.

\section{Recommendations}

The study finally recommended that Behavioural finance experts should be involved since they recognize emotions, 
herd instincts and social influences that play an important role in influencing investment leading to discrepancies between market price and fundamental value.

\section{References}

[1] Barberis, N., \& Thaler, R. (2003). A survey of behavioral finance. Handbook of the Economics of Finance, 1, 1053-1128.

[2] Bashir, T., Rasheed, S., Raftar, S., Fatima, S., \& Maqsood, S. (2013). Impact of behavioral biases on investor decision making: Male vs female. Journal of Business and Management, 10(3), 60-68.

[3] Bhamra, H. S., \& Uppal, R. (2015). Does Household Finance Matter? Small Financial Errors with Large Social Costs.

[4] Bizimana, H. (2010). Drivers that influence susceptibility to HIV infection among students of higher institute of agriculture and animal husbandry (ISAE)-Rwanda.

[5] Chaudhary, A. K. (2013). Impact of behavioural finance in investment decisions and strategies-A fresh approach. International Journal of Management Research and Business Strategy, 2(2), 85-92.

[6] Dailami, M., \& Atkin, M. (1990). Stock markets in developing countries: key issues and a research agenda (Vol. 515). World Bank Publications.

[7] Dancy, C. P. \&. Reidy, J. (2004) Statistics without maths for psychology IEEE Statistics without maths for psychology.

[8] Gholizadeh, M. H., Shakerinia, I., \& Sabet, S. Z. (2013). The role of behavioral biases on Investment Decisions Case studies: Tehran stock. International Research Journal of Applied and Basic Sciences, 4(4), 819-824.

[9] Graham, M. H. (2003). Confronting multicollinearity in ecological multiple regression. Ecology, 84(11), 2809-2815.

[10] Hilary, G., \& Menzly, L. (2006). Does past success lead analysts to become overconfident? Management science, 52(4), 489-500.

[11] Ince, H., \& Trafalis, T. B. (2007). Kernel principal component analysis and support vector machines for stock price prediction. IIE Transactions, 39(6), 629-637.

[12] Kafayat, A. (2014). Interrelationship of biases: effect investment decisions ultimately. Theoretical and Applied Economics, 21(6 (595)), 85-110.

[13] Kahneman, D., \& Lovallo, D. (1993). Timid choices and bold forecasts: A cognitive perspective on risk taking. Management science, 39(1), 17-31.

[14] Kahneman, D. and Tversky, A. (1979) Prospect Theory: An Analysis of Decision under Risk. Econometrica: Journal of the Econometric Society, 47, 263-291. http://dx.doi.org/10.2307/1914185

[15] Kidd III, C. E. (2012). The Social Implications of SubSaharan Financial Markets: Case Analysis From the Nairobi and Johannesburg Stock Exchanges Unpublished $\mathrm{PhD}$ dissertation, Howard: Howard University.

[16] Kombo, D. K., \& Tromp, D. L. (2006). A (2006). Proposal and Thesis Writing: An Introduction Nairobi: Paulines
Publication Africa.

[17] Kosnik, L. R. D. (2008). Refusing to budge: a confirmatory bias in decision making? Mind \& Society, 7(2), 193-214.

[18] Lam, M. (2004). Neural network techniques for financial performance prediction: integrating fundamental and technical analysis. Decision support systems, 37(4), 567-581.

[19] Lodhi, S. (2014). Factors influencing individual investor behaviour: An empirical study of city Karachi. Journal of Business and Management, 16(2), 68-76.

[20] Mahonye, N. (2014). Capital markets development, financial structure and economic development in Africa (Doctoral dissertation).

[21] Marchand, M. (2012) Behavioral biases in financial decision making.

[22] Mauwa, J. (2016) Determinants Of Financial Performance Of Firms Listed On The Rwanda Stock Exchange.

[23] Mawowa, S. (2013). Political Economy of Crisis, Mining and Accumulation in Zimbabwe. Unpublished PhD thesis, Durban: University of KwaZulu Natal Durban.

[24] Mbaru, J. (2003). Transforming Africa: New Pathways to Development: Selected Speeches and Papers on Financial Reform and Development. East African Publishers.

[25] Morris, M. W. (2014) Values as the essence of culture: Foundation or fallacy? Journal of Cross-Cultural Psychology, 45 (1), 14-24.

[26] Mwangi, J. M. (2016). Effect of Financial Structure on Financial Performance of Firms Listed at East Africa Securities Exchanges.

[27] Nofsinger, J. (2016). The psychology of investing. Routledge.

[28] Odera, O. (2012). Theoretical issues on the African stock markets and portfolio performance. Journal of Economics and International Finance, 4(5), 123.

[29] Onsomu, Z. N. (2014). The impact of Behavioural biases on investor decisions in Kenya: Male vs Female.

[30] Parmley, M. C. (2006). The effects of the confirmation bias on diagnostic decision making (Doctoral dissertation, Drexel University).

[31] Piesse, J., \& Hearn, B. (2005). Regional Integration Of Equity Markets In Sub-Saharan Africa. South African Journal of Economics, 73(1), 36-52.

[32] RSE. (2015). Rwanda Stock Exchange Annual Report 2015.

[33] Sadi, R., Asl, H. G., Rostami, M. R., Gholipour, A., \& Gholipour, F. (2011). Behavioral finance: the explanation of investors' personality and perceptual biases effects on financial decisions. International journal of economics and finance, 3(5), 234.

[34] Shefrin, H. (2002). Beyond greed and fear: Understanding behavioral finance and the psychology of investing. Oxford University Press on Demand.

[35] Shefrin, H. (2007,). Behavioral finance: biases, mean-variance returns, and risk premiums. In CFA Institute Conference Proceedings Quarterly (Vol. 24, No. 2, pp. 4-12). CFA Institute. 
[36] Shefrin, H. (2010). Behavioralizing finance. Foundations and Trends ${ }^{\circledR}$ in Finance, 4(1-2), 1-184.

[37] Silverman, D. (2013). Doing qualitative research: A practical handbook. SAGE Publications Limited.

[38] Subrahmanyam, A. (2008). Behavioural finance: A review and synthesis. European Financial Management, 14(1), 12-29.

[39] Sukanya, R., \& Thimmarayappa, R. (2015). Impact of Behavioural biases in Portfolio investment decision making process. International Journal of Commerce, Business and Management (IJCBM), 4(4), 1278-1289.

[40] Veeraraghavan, K., \& Anbalagan, M. (2011). Heuristic Behavior of the Investors. International. Journal of Enterprise Innovation Management Studies, 2(2), 142-149.
[41] Wasiu, O. I., \& Temitope, M. W. (2013) Financial Market Integration and Economic Growth: An Experience from Nigeria.

[42] Waweru, N. M., Mwangi, G. G., \& Parkinson, J. M. (2014). Behavioural factors influencing investment decisions in the Kenyan property market. Afro-Asian Journal of Finance and Accounting, 4(1), 26-49.

[43] Waweru, N. M., Munyoki, E., \& Uliana, E. (2008). The effects of behavioural factors in investment decision-making: A survey of institutional investors operating at the Nairobi Stock Exchange. International Journal of Business and Emerging Markets, 1(1), 24-41.

[44] Wójcik, D. (2011). The global stock market: Issuers, investors, and intermediaries in an uneven world. Oxford University Press. 